\title{
Pedagogia da autonomia na educação musical: contribuições da leitura de mundo freireana
}

Luciane da Costa Cuervo ${ }^{1} \mathbb{D}$

\section{(9) $(\Theta \Theta \Theta$}

1.Universidade Federal do Rio Grande do Sul

Luciane.cuervo@ufrgs.br

Recibido: $26 / 07 / 2021$

Revisado: 09/08/2021

Aprobado: 01/10/2021

Publicado: 01/01/2022

\section{Resumo}

Este trabalho celebra o centenário de Paulo Freire (1921-2021) discutindoa relevância de seulegado na perspectiva da pedagogia da autonomia e leitura de mundo na educação musical. O ensaio parte do conceito de curiosidade epistemológica e suas relações com a criatividade, e entrelaça pensamentos e pressupostos freireanos à formação de professores no campo da educação musical. As contribuições da obra de Freire para a educação musical fundamentam o texto, engendradas às experiências e práticas pedagógicas da autora na condução de projetos ligados à formação de professores e à educação básica e superior.

Palavras-chave: musicalidade, criatividade, formação de professoresent

Para citar este artículo: Cuervo, L. (2022). Pedagogia da autonomia na educação musical: contribuições da leitura de mundo freireana. Praxis \& Saber, 13(32), e13224. https://doi. org/10.19053/22160159.v13.n32.2022.13224 


\title{
Pedagogía de la autonomía en la educación musical: contribuciones desde la lectura de mundo freireana
}

\section{Resumen}

Este trabajo celebra el centenario de Paulo Freire (1921-2021) con una discusión sobre la relevancia de su legado desde la perspectiva de la pedagogía de la autonomía y la lectura de mundo en la educación musical. El ensayo parte del concepto de curiosidad epistemológica y su relación con la creatividad, y entrelaza los pensamientos y principios freireanos con la formación de profesores en el campo de la educación musical. Los aportes de la obra de Freire a la educación musical sustentan el texto, basados en las experiencias y prácticas pedagógicas de la autora en la realización de proyectos relacionados con la formación del profesorado y con la educación básica y superior.

Palabras clave: musicalidad, creatividad, formación de profesores

\section{Pedagogy of autonomy in music education: contributions from the Freirean reading of the world}

\begin{abstract}
This essay celebrates the centenary of the birth of Paulo Freire (1921-2021) with a discussion on the relevance of his legacy from the perspective of the pedagogy of autonomy and the reading of the world in music education. The text starts with the concept of epistemological curiosity and its connection with creativity, and intertwines Freirean thoughts and principles with the training of teachers in the field of music education. The contributions of Freire's work to music education support this text, based on the author's experiences and pedagogical practices in the implementation of projects related to teacher training and basic and higher education.
\end{abstract}

Keywords: musicality, creativity, teacher training 


\section{Curiosidade e pesquisa}

Ao celebrar o centenário de nascimento de Paulo Freire (1921-2021), este trabalho encontra motivação no legado do educador, especialmente em suas contribuições sobre a pedagogia da autonomia, contextualizadas à educação musical. Partindo do conceito de curiosidade defendido por Freire (1996) e de sua perspectiva de leitura de mundo, este texto entrelaça aspectos históricos de vida e obra do educador à sua visão epistemológica, articulando essas reflexões ao campo de atuação da autora na formação básica e continuada de professores em educação musical.

Nesta linha de pensamento, são propostas reflexões e são relatadas estratégias para implementar uma visão freireana de educação autônoma, criativa e crítica no cenário educativo-musical, que podem ser contextualizadas à educação básica, ao ensino superior e à formação de professores de música de modo geral. Nesse sentido, o artigo é enriquecido pela articulação universidade-escola em ações de ensino, pesquisa e extensão, por meio de relatos de práticas pedagógicas da autora nas modalidades presencial, a distância e de ensino remoto emergencial implementado por ocasião da pandemia de Covid-19.

Primeiramente, cabe um breve aporte histórico sobre a atuação de Freire na educação do Brasil e a projeção de seu trabalho ${ }^{1}$. Paulo Reglus Neves Freire nasceu em 1921 em Recife, no estado brasileiro de Pernambuco, vivendo até 1997 com intensa atuação intelectual. Graduado em direito pela Universidade Federal do Recife, obteve seu doutorado em Filosofia e História da Educação concedido pela mesma universidade em 1959, os quais somam-se aos mais de 30 títulos Doutor Honoris Causa, além de diversas distinções e nomeações em vida e póstumas recebidas, como o prêmio Educação pela Paz em 1986, emitido pela Unesco e o título de Patrono da Educação Brasileira (Lei no 12 612, Congresso Nacional do Brasil, 2012) no governo da presidenta Dilma Rousseff.

A importância e a projeção de sua obra, intensificada mesmo com o exílio do educador imposto pela ditadura no Brasil - a partir do golpe militar de 1964 - avessa ao seu projeto de educação popular, podem ser mensuradas por constar entre os três pensadores mais citados em trabalhos acadêmicos no mundo (Paiva, 2016). Cuervo (2021) problematiza o discurso de ódio contrário às ideias do educador, motivado por movimentos sociais e políticos de extremadireita no país que se opõem à educação popular e à conscientização social dos trabalhadores. Neste delineamento histórico, a pesquisadora demonstra as inconsistências dos argumentos desses grupos agressores e a origem, ainda na ditadura, dessa hostilidade, imputando a Freire o predicado de "subversivo" e "doutrinador marxista" como xingamentos (Cuervo, 2021).

Suas ideias foram organizadas num processo educativo popular de adultos que ficou conhecido como "Método Paulo Freire", o qual fomenta a alfabetização a partir de palavras geradoras em sua capacidade de relacionar conhecimentos prévios ao universo da comunidade, que sejam familiares e presentes na vida cotidiana dos educandos (Freire, 1967, 1970, 1989). É possível categorizar seu método em três fases, desencadeadas pela investigação das palavras-chave da realidade do educando, como palavras geradoras; em seguida, através da

1 Para mais informações, conferir o site oficial de Paulo Freire no Brasil, por ele originado: https://www.paulofreire.org/oinstituto-paulo-freire 
contextualização temática dessas palavras, trazendo então a sua conotação social e cultural no universo de sentidos que ela representa; e como culminância, por meio de rodas de conversas, "círculos de cultura" e diálogos integradores, o educando então é levado a problematizar as palavras e seus temas diante da realidade (Freire, 1967, 1970).

Erra quem pensa que suas orientações formam um conjunto fechado de regras como um método cristalizado, pois é justamente a este modelo que Freire se opõe. Também é equivocado o pensamento de limitar seus pressupostos à alfabetização de adultos, pois estes princípios são enriquecedores do processo educativo em qualquer faixa etária e podem ser transpostos a diferentes áreas do saber e esferas da educação.

Em lugar de professor, com tradições fortemente 'doadoras', o coordenador de debates. Em lugar de aula discursiva, o diálogo. Em lugar de aluno, com tradições passivas, o participante de grupo. Em lugar dos 'pontos' e de programas alienados, programação compacta, 'reduzida' e 'codificada' em unidades de aprendizado. (Freire, 1967, p. 102)

À frente do seu tempo, Freire propõe uma abordagem liberta de limitações geográficas e hierárquicas de salas de aula, de modelos expositivos centrados no professor, bem como de conteúdos expressos unicamente em livros didáticos e planejamentos pedagógicos. A competência estruturante é a autonomia, forjada no exercício cotidiano da decisão, da manifestação e da prática dialógica. Mais do que alfabetizar, Freire almeja educar, promovendo uma educação libertária por meio do diálogo, na transição da realidade ao significado simbólico. Para isso, é importante que os educandos sejam considerados sujeitos protagonistas de suas trajetórias educativas e façam o movimento de tomada de consciência em conexão com a realidade do universo ao seu redor e com as relações humanas nelas construídas (Freire, 1996). Nessa ótica, a educação é vista como um processo social e cidadão, crítico e colaborativo, um direito de todas as pessoas - um mecanismo de mobilidade e mobilização social e, portanto, política (Freire, 1967, 1996).

Em sua visão, entende a educação como uma ação política, de ser e estar critica e conscientemente no mundo, atuando e colaborando para a sua transformação. A tomada de consciência por parte do educando, para Freire (1996), ocorre no resgate e potencialização da curiosidade, inicialmente espontânea tecida no senso comum, a qual amadurece em sua natureza investigativa até a chegada à curiosidade epistemológica.

Freire (1996) acredita que o respeito aos saberes dos educandos precisa considerar a experiência prática e prévia ao processo educativo. Para ele, a trajetória rumo à tomada de consciência e criticidade diante do mundo, numa educação libertária, passa pelo exercício do rigor metódico na relação do sujeito com o objeto (Freire, 1996, p. 31). Nessa perspectiva, os saberes populares precisam ser contemplados na trajetória de construção do conhecimento, cumulativamente a novos saberes e de forma contextualizada à realidade circundante:

Não há para mim, na diferença e na "distância" entre a ingenuidade e a criticidade, entre o saber de pura experiência feito e o que resulta dos procedimentos metodicamente rigorosos, uma ruptura, mas uma superação. A superação e não a ruptura se dá na medida em que a curiosidade ingênua, sem deixar de ser curiosidade, pelo contrário, continuando a ser curiosidade, se criticiza. (Freire, 1996, p. 31) 
Um dos conceitos basilares discutidos por Freire, portanto, é a curiosidade. O educador entende que, sem espaço para ela, o diálogo entre o senso comum e o rigor científico ficaria limitado em suas fronteiras do saber, restringindo também o processo educativo (Freire, 1996). Ele acredita que o ponto de partida de todo ato pensante de leitura de mundo consiste na curiosidade espontânea, cujos estudos e experiências nos levam a aprofundar seus ensinamentos até o que ele chama de curiosidade epistemológica (Freire, 1996), "a que, tomando distância do objeto, dele se "aproxima" com o ímpeto e o gosto de desvelá-lo" (Freire, 1993, p. 29).

$\mathrm{Na}$ experiência docente da autora, tem sido comum encontrar estudantes de graduação em música, mesmo na licenciatura ${ }^{2}$, que possuem foco extremamente restrito à execução musical, pois julgam que saber fazer e ensinar música referem-se quase que, exclusivamente, a saber tocar muito bem um instrumento musical. Repetindo o modelo conservatorial que tanto domina o meio acadêmico ainda hoje, perpetuam-se práticas, comportamentos e conteúdos os quais seguem uma abordagem historicamente ligada a conservatórios de música na Europa, cuja técnica se sobrepõe à expressividade e ao sentido do fazer musical. Conforme discute a educadora musical Penna (1995), esse modelo promulga o "enfoque da técnica como finalidade em si mesma, tendo por meta o virtuosismo" (p. 134).

Este conjunto de procedimentos e valores que preservam tradições ocidentais, possui, de modo geral, um repertório musical eurocentrado "erudito" de poucos séculos da história proposto unicamente pelo professor de música, registrado em partitura convencional pentagramática e sem abertura aos saberes populares ou aos anseios do corpo discente. A estruturação deste formato de trabalho se baseia no domínio docente em relação à vida musical discente, decidindo qual repertório, que tipo de sonoridade e quais estratégias de estudo serão empregadas de forma unidirecional da performance. Sem espaço para reflexão, diálogo e criação do educando, situa-se longe da compreensão de curiosidade investigativa como apregoa Freire (1996), portanto essa concepção vai de encontro aos pressupostos freireanos de autonomia e leitura de mundo.

Uma trajetória formativa focada na execução musical pode deixar de desenvolver diferentes competências e habilidades nas mais variadas interfaces do fazer musical, diminuindo - ou até anulando - o espaço do educando em pensar criticamente sobre sua formação. A importância de transcender o ato de tocar em suas execuções mecânicas e técnicas é ainda mais evidente em cursos de formação de novos professores, pois ser educador está intrinsecamente ligado ao perfil pesquisador, como nos ensina Freire $(1993,1996)$. Em suas palavras:

No meu entender o que há de pesquisador no professor não é uma qualidade ou uma forma de ser ou de atuar que se acrescente à de ensinar. Faz parte da natureza da prática docente a indagação, a busca, a pesquisa. O que se precisa é que, em sua formação permanente, o professor se perceba e se assuma, porque professor, como pesquisador. (Freire, 1996, p. 14)

A criatividade, nesse sentido, está conectada à curiosidade e às possibilidades de interpretação do mundo lido, pois a leitura de mundo é mobilizada pela pergunta, na busca

2 O curso de formação básica inicial de professores chama-se, no Brasil, de Licenciatura. É oferecido na esfera da educação superior - graduação universitária - e concede ao formado autorização para atuar como docente no ensino fundamental, profissionalizando e ensino médio a partir da área de formação. 
do conhecimento. Como argumenta Freire (1993), é preciso correr riscos na construção do conhecimento, processo que se move pela curiosidade, pela experimentação e pela criatividade.

A educação musical que se alinha aos pressupostos freireanos possui diálogo dinâmico entre as partes envolvidas, desde seu planejamento, pois cada agente desse processo transparente encampa o comprometimento com a aprendizagem.

\section{Leitura de mundo e autonomia}

O conhecimento se nutre da leitura e da reflexão. A atividade de leitura e a interpretação do que é lido exigem diferentes competências cognitivas do ser humano, e são umas das formas mais complexas e profundas de exercício mental. Ler, decodificando as palavras e as frases, é diferente de compreender, mas consiste numa das etapas primordiais desse processo dinâmico. Podemos fazer uma analogia com a partitura musical: enquanto a leitura de uma música registrada na partitura tradicional é algo que pode ser feito mecanicamente com o domínio técnico daquela linguagem convencionada - por exemplo, de um pentagrama e suas notas musicais - a interpretação expressiva da obra musical manifesta um nível muito mais avançado de envolvimento com o mesmo conteúdo.

A leitura da palavra é apenas um dos inúmeros recursos que o indivíduo mobiliza no contato com um texto - a palavra é agrupada como um conjunto de letras, assim como o inciso em música é um grupo de notas musicais com sentido. Freire (1989) ressalta que o ato de ler textos, no entanto, precisa ser transcendido pelo processo de "ler o mundo", que ele crê ser algo que precede a leitura da palavra:

De alguma maneira, porém, podemos ir mais longe e dizer que a leitura da palavra não é apenas precedida pela leitura do mundo, mas por uma certa forma de "escrevê-lo" ou de "reescrevê-lo", quer dizer, de transformá-lo através de nossa prática consciente. (p. 22)

De acordo com Freire (1996), teoria e prática estão interligadas - assim como o rigor científico e a curiosidade, o pensamento e a ação -, pois a práxis progressista educativa não separa o conteúdo da forma de "como aprender". A sua pedagogia da autonomia (1996) e a sua pedagogia crítica (1970) se alinham na potencialização dos saberes dos educandos, processo no qual o professor é um indagador, um provocador de reflexão e questionamento. A tomada de consciência assume uma nova dimensão na vida do educando quando este percebe que sabe "coisas" relevantes, quando ele então "sabe que sabe" e pode, com esse saber, intervir no mundo ao seu redor e transformá-lo.

A educação é um conceito amplo, definido e empregado de muitas formas diferentes, conforme a visão de mundo e aos objetivos de um processo educativo em seu contexto social, temporal e físico. A origem etimológica da palavra advém do verbo latino educare, no qual ex- significa "exterior" e ducere, "conduzir". Educação - educatǐo, ōnis - está relacionada com instruir, criar e nutrir. Podemos interpretar, assim, o processo educativo como a transcendência de um ponto ao outro, de um contexto para uma nova realidade, de si mesmo para o mundo exterior. Nessa ótica, podemos compreender o conceito de educação como algo que amplia fronteiras da mente humana.

A capacidade crítica é um dos pressupostos freireanos mais vigorosos para a educação 
e, também, um dos mais temidos pelas elites econômicas dominantes. Em música, pode ser traduzida pelo estudo consciente das culturas e manifestações musicais devidamente contextualizadas ao seu período histórico e social, pela valorização das histórias de vida e emoções ligadas a elas, pelo que Freire (1996) entende por identidade cultural e leitura de mundo, marcadamente pelo diálogo em todas as etapas de construção da aprendizagem musical. Por outras palavras, pode ser traduzida pela capacidade de problematização das temáticas abrangidas nas letras das canções e mobilizações sociais que se deram a partir da música, como as canções de protesto da música popular, mas, acima de tudo, ao entender a sua trajetória no mundo e a visão política que ela representa e reflete.

Alguns artistas se inspiram não mais na vida fácil da burguesia, mas na vida difícil e dura do povo; na poesia, já não se cantam apenas os amores perdidos nem se fala de camponeses e operários urbanos como abstrações, mas como homens e mulheres concretos, em uma realidade concreta. (Freire, 1981, p. 60)

O diálogo universidade-escola, constituinte de uma dinâmica que se retroalimenta, precisa estar ciente da necessidade de fomentar capacidades integradoras de práticas de inclusão e convivência social, de respeito à diversidade humana em suas interfaces de gênero, cultura, religião e outras e na defesa dos direitos humanos por meio do processo educativo. A despeito deste cenário, tão diverso e complexo, Bolaños (2016) problematiza a necessidade de superar as fronteiras e estagnações do conhecimento científico-acadêmico, muitas vezes enclausurado e distante da realidade escolar. O autor defende uma abordagem investigativa na sala de aula, convocando a universidade a assumir seu papel na formação de professores atentos a essa demanda.

Esse delineamento da formação de professores passa, inevitavelmente, pela necessidade de fomento à autonomia de pensamento, à postura crítica diante da realidade, contrária à educação passiva, omissa e alienante, a qual foi chamada por Freire como educação bancária. O conceito de autonomia para Freire pode ser (re)discutido sob a perspectiva do diálogo e da reflexão sobre si mesmo em sua leitura de mundo e sua tomada de consciência. Essa liberdade demanda do educando a responsabilidade pela construção de seu aprendizado (Freire, 1996).

Diversos educadores musicais vêm articulando o legado freireano em suas práticas pedagógicas. Abrahams (2005) discute a pedagogia crítica de Freire no contexto da educação musical, e entende que o papel do educador também passa por fomentar o despertar da musicalidade do educando, dando espaço para atuarem como artistas, numa parceria horizontal. Essa dinâmica pode promover resultados transformadores na esfera pessoal de todos os agentes envolvidos (Abrahams, 2005, 2007). Schmidt (2005), em concordância com essa visão, acredita que a educação musical já possui, pela sua natureza, potencial transformador em diferentes realidades sociais. Contudo, para que isso ocorra, a educação musical demanda superar os aspectos formais da sintaxe musical, da estética e da eficácia, pois "precisa se relacionar com as realidades de indivíduos e comunidades nas quais se engaja. Não deve apenas estabelecer seu valor em conexões cognitivas e emocionais por si só, mas também busca por relações sociais e, portanto, pessoais, transformação" (Schmidt, 2005, p. 4).

Sobre a necessidade de contextualizar a educação musical como abordagem de 
resistência e conscientização social, Talbot e Williams (2019) sustentam que os diferentes perfis e comportamentos na sala de aula de música podem ser enriquecidos por uma linha pedagógica que fortaleça o senso crítico da realidade. A resolução de problemas, o debate de ideias, a construção coletiva e colaborativa de conteúdos e novas aprendizagens - para estes pesquisadores - são concomitantes na abordagem educativo-musical baseada nos pressupostos freireanos.

Nas palavras de Freire (1996): "Distanciando-se do seu mundo vivido, problematizando-o, 'descodificando-o' criticamente, no mesmo movimento da consciência o homem se re-descobre como sujeito instaurador desse mundo de sua experiência" (p. 15). Ele entende que, a partir desse processo, o sujeito progride de um estado ingênuo para despertar de maneira crítica, assumindo seu papel social e histórico.

A tomada de decisão remete à acolhida das consequências, mas o exercício de decidir é crucial para aprender a decidir. Ou seja, a autonomia não chega antes desse exercício da decisão (Freire, 1996).

A autonomia, enquanto amadurecimento do ser para si, é processo, é vir a ser. Não ocorre em data marcada. É neste sentido que uma pedagogia da autonomia tem de estar centrada em experiências estimuladoras da decisão e da responsabilidade, vale dizer, em experiências respeitosas da liberdade. (Freire, 1996, p. 67)

Benedict e Schmidt (2008) discutem as políticas conceituais a partir de contribuições de Freire, provocando a problematização sobre o papel do educador musical, muitas vezes renegado a pressões institucionais, padronizadas, ou mesmo de seus patrocinadores e financiadores. Assim, os pesquisadores chamam à responsabilidade dos educadores musicais para a prática crítica na educação musical, a qual deveria partir de si mesmos primeiramente.

O livro que inspira esta seção reúne algumas das principais discussões de Freire (1996) sobre o tema da autonomia dos educandos. Pedagogia da Autonomia é dividido em três capítulos: (1) Não há docência sem discência, (2) Ensinar não é transferir conhecimento e (3) Ensinar é uma especificidade humana. A publicação está subdividida em princípios da prática educativa, com exímia habilidade de sintetização por parte do educador, profundos ensinamentos sobre a educação do ser crítico, autônomo e atuante. Do capítulo 1, destacando-se a importância dos saberes discentes e do conhecimento deles por parte do educador, Freire (1996) aponta nove tópicos de reflexão, os quais, por si só, já trazem em seus títulos orientações relevantes:

- Ensinar exige rigorosidade metódica.

- Ensinar exige pesquisa.

- Ensinar respeito aos saberes dos educandos.

- Ensinar exige criticidade.

- Ensinar exige estética e ética.

- Ensinar exige a corporificação das palavras pelo exemplo.

- Ensinar exige risco, aceitação do novo e rejeição a qualquer forma de discriminação. 
- Ensinar exige reflexão crítica sobre a prática.

- Ensinar exige reconhecimento e a assunção da identidade cultural. (pp. 5-6)

Figura 1

Diagrama de saberes para a prática educativa freireana

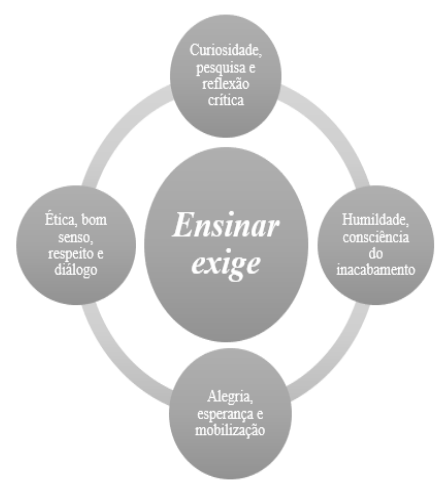

Nota. Adaptada de Freire (1996).

Na Pedagogia da Autonomia (Freire, 1996), é primordial o respeito à identidade cultural individual e de classe dos educandos, cujo processo educativo deve incentivar o educando a assumir-se como ser histórico, criador, pensante, crítico e criativo. Conforme explica: "A assunção de nós mesmos não significa a exclusão dos outros. É a 'outredade' do 'não eu', ou do $t u$, que me faz assumir a radicalidade do meu eu" (p. 41).

Sobre diferentes formas de interação e incentivo à autonomia, Green (2008) propõe que as preferências dos educandos devem basear a construção do repertório musical. Em sua pesquisa, a educadora musical percebeu que abordagens informais ${ }^{3} \mathrm{em}$ sala de aula trouxeram mudanças positivas na forma de ensinar na percepção dos docentes, assim como possibilitaram aos educandos uma tomada de consciência sobre as suas próprias musicalidades, sejam elas vivenciadas anteriormente em projetos formais, não formais ou informais de educação musical.

A pedagogia crítica em educação musical também foi discutida por Slamkowski (2015), cuja conclusão de investigação entre docentes foi entender que os currículos podem ser construídos em conjunto no diálogo docente-discente, tornando então a sala de aula um espaço mais democrático de construção e partilha de saberes.

Numa abordagem desencadeada por palavras e temas geradores, Freire (1981) encontra o diálogo entre objetividade e subjetividade, não alienando ou ignorando um conceito ou o outro. Conforme prediz: "Toda prática educativa implica numa concepção dos seres humanos e do mundo" (Freire, 1981, p. 53), entendendo que a cultura e a arte são mecanismos de mobilização e transformação, como recursos de fomento à consciência crítica sobre a realidade.

3 Adota-se o conceito de Gadotti (2005) sobre abordagens não formais/informais, que, para ele, são mais livres, com flexibilidade hierárquica e temporal, e menos dominada por aspectos administrativos e burocráticos. O autor problematiza o termo informal, pois acredita que todo processo educativo possui aspectos formais de desenvolvimento, seja curricular ou não, dentro, fora ou paralelamente à escola. 
A formação de professores é um processo educativo longo porque é permanente, de diferentes nuances e esferas da vida docente. O estudante em idade escolar observa seus professores atentamente, e pode se encontrar ali uma fagulha que inicia o fascínio pelo ensinar e aprender. Formalmente, passa a ser sistematizada a partir de cursos como magistério e graduação de natureza pedagógica, que no Brasil chamamos de licenciaturas. Mas a formação de professores também ocorre pela permanente capacitação, em cursos livres, políticas públicas e tantas outras iniciativas que deveriam fazer parte da vida profissional docente. Conforme explana Cuervo (2015), é importante lembrar que cursistas de ações formativas docentes envolvem pessoas em atividade profissional - recente ou antiga, cujas trajetórias de vida e experiências não podem ser desconsideradas.

Por vezes é preciso resgatar experiências e promover a reflexão sobre elas; noutros momentos é necessário promover a desconstrução de paradigmas e preconceitos enraizados no fazer docente.

\section{Práticas pedagógicas em educação musical}

Há uma série de estratégias pedagógicas promovidas pela autora na perspectiva crítica e criativa em educação musical, as quais se refletem nos planejamentos e execuções de disciplinas do curso de Licenciatura e Bacharelado em Música, em cursos de capacitação de professores na esfera da extensão ${ }^{4}$ e do Programa Institucional de Bolsas de Iniciação à Docência coordenados e ministrados pela autora na Universidade Federal do Rio Grande do Sul (UFRGS). Nessa linha de atuação, propõe-se uma organização estruturante que prioriza a participação do estudante em todo processo educativo, de forma colaborativa e crítica, iniciando pelas discussões de documentos norteadores - como os planos de ensino - , e enriquecendo-se pelas reflexões sobre suas próprias trajetórias de vida e bagagens socioculturais.

Em espaços de fóruns de discussão abertos no ambiente virtual de ensino e aprendizagem Moodle Acadêmico e nas rodas de conversas dos encontros presenciais - antes da pandemia e online - durante - , foram abertos tópicos de manifestação de expectativas dos educandos. Estes são convidados a comentar a proposta de Plano de Ensino, como um documento que apresenta uma perspectiva da condução docente para o semestre letivo, mas considerado um recurso aberto à colaboração, crítica e sugestão do corpo discente. A partir dessas conversas, muitas vezes há transformações e adaptações do planejamento pedagógico, buscando contemplar anseios de formação e expectativas de conteúdo e temas geradores propostos pelos estudantes a partir de suas referências culturais.

Freire (1996) reitera a importância de mecanismos de interação e aproximação ao considerar a experiência prévia e valores de vida do educando no planejamento pedagógico com genuíno interesse nessa assunção da identidade cultural. Em afinidade com esses pressupostos, Gainza (1988) argumenta que o conhecimento do aluno por parte do educador musical é um elemento fundamental para a construção de um processo sensível e integrador, sugerindo que seja criada uma ficha orientadora para observação da conduta musical, partindo da história individual, a qual antecede a seção de recepção musical, quando ela elenca fatores de estimulação e motivação, sendo eles: interesse, atenção, concentração e memória.

4 Curso Cultura Digital e Educação: do real ao virtual, realizado via Pró-Reitoria de Extensão da UFRGS, direcionado a professores e estudantes de licenciatura, com duração total de 45 horas-aula e aberto para a comunidade. 
Unindo essas ideias, em disciplinas como Introdução à Educação Musical, a autora vem implementando - como uma das primeiras estratégias de integração de novos estudantes ao curso - um questionário chamado Histórico de Musicalidades, no qual se instiga o resgate de experiências e reflexões dos educandos envolvendo a musicalidade, como um exercício de resgate de memórias e registro sobre a presença e importância da música na vida dos estudantes, argumentado como um mecanismo de enriquecimento do planejamento e das práticas pedagógicas. Com suas identidades preservadas e participação espontânea, o recurso vem alcançando excelente adesão, possuindo, portanto, um caráter didático e investigativo. Nele foram propostas questões como:

- Você lembra quando começou seu interesse mais profundo por música? Poderia partilhar essa lembrança?

- Você possui alguma experiência positivamente marcante envolvendo a música? Poderia relatá-la?

- Você teve acesso à educação musical na formação escolar - educação básica?

- Você considera que a música exerce um papel importante em sua vida? Por quê?

Além de fomentar a reflexão e o registro dessas narrativas dos educandos, esses questionários também se mostram eficazes mecanismos de diagnóstico das turmas, promovendo o conhecimento, por parte da educadora, sobre os perfis dos educandos e as suas trajetórias ao longo do curso. Esse tipo de dado de coleta, que enxerga a sala de aula como um espaço de permanente investigação científica, enriquece o planejamento pedagógico a cada nova turma, demonstrando a necessária flexibilização de conteúdos e práticas pedagógicas em consonância com as expectativas e demandas dos educandos.

Advogando pela educação emancipatória na linha da pedagogia crítica, também Abrahams (2005) propõe as seguintes perguntas a serem feitas durante o planejamento das aulas de música:

- "Quem eu sou?

- Quem são meus estudantes?

- Em que eles podem tornar-se?

- Em que podemos nos transformar juntos?" (p. 9).

Estas perguntas problematizadoras não possuem respostas certas ou exatas, mas que podem mobilizar as discussões na sala de aula, numa pedagogia que fomenta a autonomia de pensamento, tanto do ser docente quanto do estudante e deste coletivo.

Em afinidade com esses pressupostos, se tratou da proposição do questionário Identidade Cultural, o qual - devidamente adaptado ao ensino remoto imposto pela pandemia de Covid-19 - foi proposto via Google Forms e Apresentações, dispostos na unidade de apresentação do Google Sala de Aula ${ }^{5}$ e Moodle Acadêmico. Neste material, os cursistas foram convidados a

5 A autora faz uso do Moodle Acadêmico Institucional da UFRGS desde 2009, como recurso complementar das aulas presenciais. Com a chegada da pandemia de Covid-19 e implementação da modalidade remota em caráter emergencial, foi então somado o 
responder questões lúdicas sobre seus perfis de leitura, preferências culturais, audiovisuais e culinárias, estados emocionais (gráfico 1) e impacto da quarentena, hábitos de consumo de música e outras produções artísticas, inclusive enviando links de áudios, vídeos e imagens que definiam suas predileções. Na esfera da graduação, também foi proposta a construção de acervos de imagens e dados, como registro de referências culturais pessoais, com uso de aplicativos de nuvem de palavras (figura 2).

\section{Gráfico 1}

Levantamento de estados emocionais

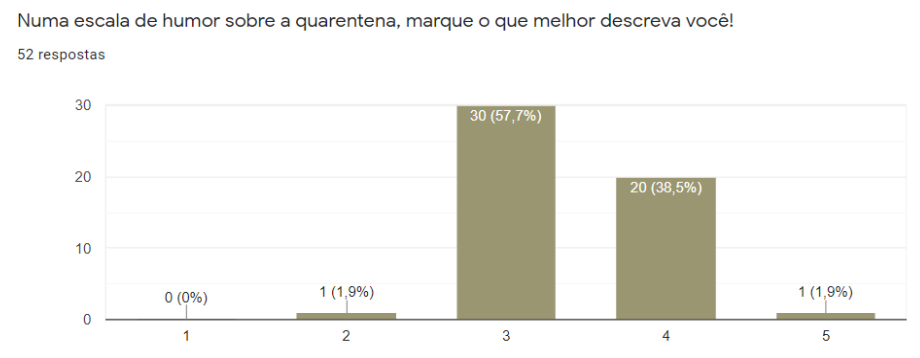

Em função da necessidade abrupta de suspensão das aulas presenciais, substituídas então pelo ensino remoto emergencial na UFRGS (Rodrigues \& Cuervo, 2021), estratégias antes experienciadas em aulas cujos cursistas estavam no mesmo espaço geográfico e tinham a possibilidade de realizar atividades demandando contato físico agora precisaram ser adaptadas ao distanciamento remoto em ações síncronas e assíncronas.

\section{Figura 2}

Nuvem de palavras concebida por estudante de graduação em música

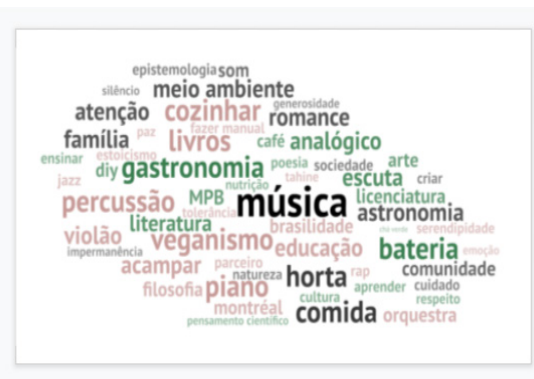

No mapa de imagens (figura 3), foi solicitado um conjunto de referências a partir de palavras: uma imagem, uma música, um filme, um lugar, um artista, uma comida, um objeto, um hobby, uma pessoa, um momento.

Após esses registros, foram incentivados debates sobre a realização da atividade, de escuta da avaliação e autoavaliação dos estudantes. Pareceu um consenso a ideia de que seria inicialmente algo simples de ser concebido, mas essas atividades mobilizaram memórias afetivas, experiências e relações entre vivências e pessoas a partir da exposição dessas referências pessoais e suas trajetórias de musicalidade.

Google Classroom como principal plataforma dos cursos de extensão, considerando o público externo e heterogêneo que participa de ações formadoras dessa natureza. 
Outra ferramenta muito bem recebida pelo corpo discente foi a elaboração autoral de podcast $^{6}$, como sequências de pequenos episódios envolvendo temas livres no contexto da educação musical. $\mathrm{Na}$ etapa de contato com o tema, foram apresentados diversos exemplos de podcast na educação musical, assim como foi discutido o conceito e suas tecnologias, com partilhas de experiências e experimentações sobre diferentes recursos da cultura digital. Ao final do semestre, cada grupo de estudantes apresentou a sua série de episódios, comentando sobre o processo de construção, dinâmica de trabalho e critérios de escolha e elaboração do formato. Os links de acesso foram reunidos num arquivo coletivo e colaborativo editável - neste caso, pelo Jamboard ${ }^{7}$ - e disponibilizados para a turma. Relatos recorrentemente mencionavam essas experiências de autoria colaborativa como um despertar de reflexões e manifestações, bem como o questionamento sobre os diferentes tipos de musicalidade que permeiam a vida dos sujeitos em seus contextos culturais.

Figura 3

Mapa de imagem concebido por estudante de graduação em música

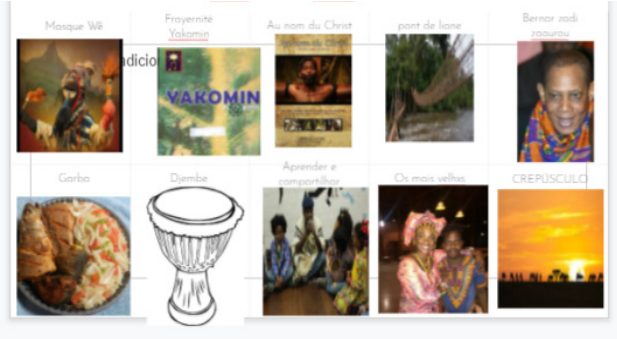

Importante dizer que o conceito de musicalidade é central na atuação investigativa e docente da autora, considerado como uma capacidade humana, natural à espécie, presente em todas os grupos sociais conhecidos (Cuervo et al., 2019). Nesse sentido, todos são considerados como seres musicais, e o próprio conceito de musicalidade é entendido como força motriz da tomada de consciência sobre este campo formativo. Conforme discutem os autores, a ligação do conceito de musicalidade com a vida e o tempo presente se manifesta em comportamentos musicais dos sujeitos em seus grupos sociais.

Numa perspectiva mais ampla, Levitin (2016) explica a história da humanidade entrelaçada por seis categorias principais de cantos no mundo: amizade, divertimento, conforto, conhecimento, religião e amor. $\mathrm{O}$ resgate das canções e seus significados nas vidas dos educandos carrega em si um conjunto de memórias afetivas, experiências de vida, saberes e práticas que contribuem para que seja conscientizada a importância da música em suas vidas.

Outro viés das estratégias de fomento à autonomia na educação musical parte da implementação de recursos colaborativos de produção autoral, promovendo o educando a protagonista do conteúdo e da forma como ele se organiza e se apresenta numa disciplina, que avalia colegas e docente, e se autoavalia. Em Tecnologias Aplicadas à Educação Musical, ministrada pela autora e outros quatro professores convidados, essa colaboratividade foi levada

6 O termo podcast une duas palavras: iPod e broadcast - transmissão originalmente via rádio -, tendo surgido em 2004 com o ex-VJ da MTV Adam Curry.

7 Aplicativo de elaboração colaborativa e com possibilidade de uso síncrono e assíncrono, dentro do pacote educacional Google. 
a um nível radical, exemplificada desde a configuração das parcerias docentes, da construção do Plano de Ensino - documento aberto às expectativas e sugestões do corpo discente, bem como o fomento da reflexão sobre o uso crítico das tecnologias no campo da educação musical. Foram estudados e discutidos conceitos como a obsolescência programada, desobediência tecnológica (Oroza, 2012) e gambiarra sonora, com aporte teórico e atividades práticas em constante remodelação ao longo do semestre letivo. Oroza (2012) ensina a repensar a estética de um objeto e a desapegar-se de sua aparência e função originais, já debilitadas, em conceitos como restauro, refuncionalização e recriação, aplicados ao mundo da arte. Esse viés desperta o uso crítico das novas tecnologias digitais e fortalece uma postura de resistência à precariedade, ao consumo e à obsolescência programada, que também se vivenciam em música.

Inspirados por essas discussões, foram desenvolvidas uma série de produções resultantes pela turma, individual e coletivamente, sendo apresentados objetos virtuais de manipulação sonora a partir de peças e ideias do cotidiano, reaproveitamento em processos criativos, objetos virtuais de aprendizagem, de cunho didático, recursos em gameficação e outros.

No incentivo da produção de material didático pelos estudantes de graduação em contribuição ao campo da educação musical, Cuervo (2020) concebeu e promoveu o projeto de publicação Laboratório de Musicalidades: cantarolando. Nessa direção, convidou estudantes de Licenciatura em Música participantes de disciplinas como Análise e Produção de Materiais Didáticos em Educação Musical, para que pensassem em canções que fossem marcantes para si, elaborando propostas pedagógicas baseadas nesse repertório. Dessa maneira, nasceu um caderno de 21 canções, no qual apresenta-se a origem delas ou explanação de sua criação no caso das originais produzidas para o projeto, partituras cifradas e sugestões de atividades pedagógicas. Voltado ao público em geral, teve como critério de construção "apresentar pequenas obras para serem cantadas em formato solo ou em grupos vocais, com a possibilidade de acompanhamento de instrumento harmônico, constituídas por letras e formas musicais acessíveis" (p. 8). Essa produção, acima de tudo, foi construída num processo envolvendo estudantes de licenciatura como autores e avaliadores de uma publicação formal da universidade. Isto exemplifica o alto nível de engajamento que pode provocar um projeto colaborativo que parte das experiências e produções discentes.

Ações dessa natureza encontram respaldo em estudos de Green (2008), quando afirma que se acentuam os potenciais de autonomia dos estudantes quando estes tomam parte das práticas de aprendizagem, tornando o processo mais prazeroso e mais eficiente.

De modo a fomentar o estudo da tradição oral em música, outra atividade proposta consiste na pesquisa, apresentação e prática de uma canção devidamente pensada em seu contexto sociocultural. Com a proposição de categorizações como "cantos de protesto", "cantos de lamento", "cantos de amor", "cantos de trabalho" entre outras, fundamentadas em estudos de Levitin (2016) e Cuervo et al. (2019), os estudantes são incentivados a adentrarem nos vestígios culturais dessas manifestações de musicalidade em diferentes povos do mundo. De acordo com a avaliação da disciplina Práticas Vocais para a Educação Musical, na qual foi implementada essa estratégia, a turma escolheu essa atividade como a preferida em relação ao semestre letivo.

Essa abordagem aberta às interações e interlocuções de diferentes narrativas de nossos 
estudantes e docentes em música passa pela necessidade de compreensão do conceito de inacabamento apregoado por Freire (1996). Entendendo que somos seres inacabados, e que é muito bom sermos assim, Freire (1996) advoga o saber em construção, o professor que compreende - com humildade —, que aprende ao ensinar, assim como o educando, que ensina ao aprender. Essa incompletude é considerada por ele tão natural quanto a própria vida.

Aqui chegamos ao ponto de que devêssemos ter partido. O do inacabamento do ser humano. Na verdade, o inacabamento do ser ou a sua inconclusão é próprio da experiência vital. Onde há vida, há inacabamento. Mas só entre mulheres e homens o inacabamento se tornou consciente. (p. 50)

Este conceito de inacabamento, tão caro à visão de Freire (1996), passa, necessariamente, pelo entendimento da impermanência como estado de ser. É uma forma, também, de contemplar e amenizar sentimentos de angústia, de autocrítica e de ansiedade na construção dos saberes, pois o conceito de inacabamento mostra que somos seres incompletos enquanto essência humana, enquanto abertos à novidade e reflexivos pelas trajetórias vividas.

A compreensão deste conceito parece ter assumido maior importância ainda em tempos de quarentena e ensino remoto emergencial, considerando que demandou novas competências para os docentes, mesmo para aqueles acostumados com recursos inerentes à cultura digital (Rodrigues \& Cuervo, 2021). Já por parte dos estudantes, a ideia de repensar áreas e estratégias de estudos, bem como novas funções para recursos tecnológicos em sua realidade de aprendizagem em formato síncrono e assíncrono de música, causou enorme desconforto em muitos casos, como investigaram Cuervo e Santiago (2020).

O campo da música, pela natureza própria de fazer coletivo e colaborativo, de práticas que exigem sincronicidade e partilhas nas mais diversas esferas do fazer musical, sofreu um grande abalo pela pandemia de Covid-19 (Cuervo \& Santiago, 2020). Os cursos tradicionais de licenciatura em música e formação de professores não se encontravam preparados para tamanho desafio, pois o diálogo com as novas tecnologias digitais ainda era carente de espaço no meio acadêmico (Rodrigues \& Cuervo, 2021).

Contudo, quando se encara a formação de professores, os processos de ensino e a aprendizagem de modo geral, como dinâmicas abertas em permanente construção, constituídas por seres e trajetórias inacabados, se entende que é da natureza educativa essa característica. Freire (1996) nos impele a entender que é da natureza humana essa incompletude, e que essa essência se enriquece no diálogo e se constitui com o outro e com o mundo.

Essas estratégias em caráter experimental no campo de formação de professores de música dialogam de forma intensa aos pressupostos apresentados por Freire em suas obras e discussões. Dar voz aos estudantes e promover um espaço ativo de contribuição e responsabilidade pelo seu próprio processo de aprendizagem - nessa troca do ensinar e aprender, do diálogo e do exercício crítico e autocrítico - se mostram recursos mobilizadores da tomada de consciência, de um despertar de suas capacidades e protagonismo. 


\section{Considerações em elisão}

Como um ponto de elisão em música, que conclui uma ideia e impulsiona para novas ações, a pedagogia da autonomia é um estado de ebulição e construção flexível, mas permanente. $\mathrm{O}$ legado freireano ainda possui muitos vieses a serem explorados nos diferentes campos do saber, mas depreende-se grandes lições para nós, educadores musicais. A ruptura com repertórios e metodologias estanques, que perpetuam e limitam as ações e os pensamentos criativos tanto da vida docente quanto discente, é um exemplo. A necessidade de repensar nossos planejamentos pedagógicos, encarando-os como documentos abertos às ressonâncias das trajetórias de vida de nossos estudantes é exercício premente na construção de nossos currículos acadêmicos.

Freire nos ensina a ler o mundo em sua complexidade, sem perder de vista as coisas simples da vida. Tudo passa pela sensibilidade perceptiva, pela prática dialética diante da construção de saberes e pela consciência do inacabamento. Defendendo que não existe educação neutra, e transpondo essa ideia para a educação musical - cujo acesso e qualidade é tão discrepante nas sociedades urbanizadas no mundo - , ele desperta a defesa da justiça social. Entendendo que a curiosidade é inata ao ser humano, se nutre desta para nos mostrar caminhos de construção do conhecimento científico, unindo saberes populares às discussões de rigor acadêmico com a mesma fluência e acessibilidade com as quais encarna suas ideias.

Ao defender a educação para a autonomia e emancipação do pensamento, a criticidade, a tomada de consciência sobre os seres históricos e sociais que somos, Freire nos mobiliza a sair de nossas zonas de conforto e a confrontar nossas angústias e revoltas. Ainda assim, não nos nega a necessidade de alegria, de esperançar - de modo ativo em busca de um mundo mais dialógico, mais justo e mais equânime nas relações humanas e acessos materiais.

Busca-se, assim, ensinar e aprender musicalidade, ou melhor, práticas e manifestações de musicalidades, contemplando processos criativos e apreciação crítica, tão cruciais do fazer musical, entendendo a performance como um processo histórico e social, não um produto abstraído de sentido. $\mathrm{O}$ anseio pelo fomento à tomada de consciência crítica e autonomia sobre uma educação musical dialógica, criativa e politicamente contextualizada, enfim, resume algumas das contribuições para a área do legado de Paulo Freire.

\section{Referências}

Abrahams, F. (2005). The application of critical pedagogy to music teaching and learning. Visions of Research in Music Education, 6, 1-16.

Abrahams, F. (2007). Musicing Paulo Freire: A critical pedagogy for music education. Em P. Mclaren, \& J. Kincheloe (Orgs.),Critical Pedagogy: Where are we now? Counterpoints: studies in the postmodern theory of education (pp. 223-237). Peter Lang Publishing.

Benedict, C., \& Schmidt, P. (2008). Pedagogias críticas e práticas músico-educativas: compartilhando histórias práticas, políticas e conceituais. Revista da Abem, 16(20), 7-17. http://www. abemeducacaomusical.com.br/revistas/revistaabem/index.php/revistaabem/article/view/244/176

Bolaños, J. (2016). El docente ante el oficio de investigar en el aula. Praxis \& Saber, 7(15), 63-80. https://doi.org/10.19053/22160159.v7.n15.2016.5723 
Congresso Nacional do Brasil. (2012, 13 de abril). Lei $n^{\circ} 12$ 612. Declara o educador Paulo Freire Patrono da Educação Brasileira. http://www.planalto.gov.br/ccivil_03/_Ato2011-2014/2012/Lei/L12612.htm

Cuervo, L. (2015) Educação para a paz na formação de professores. Em L Cuervo, \& D. Porto (Orgs), Escolas da paz: reflexões e práticas de professores da educação básica (pp. 11-18). UFRGS.

Cuervo, L. (2020). Laboratório de Musicalidades: cantarolando. UFRGS

Cuervo, L. (2021). Educação para a paz em tempos de ódio no Brasil: contribuições epistemológicas freireanas [Palestra]. Congreso Pedagogía Cuba 2021: Encuentro Internacional por la Unidad de los Educadores.Virtual.https://trabajos.pedagogiacuba.com/trabajos/22Educa\%C3\%A7\%C3\%A3o\%20 para $\% 20$ a $\% 20$ paz $\% 20$ em $\% 20$ tempos $\% 20$ de $\% 20 \%$ C $3 \%$ B 3 dio $\% 20$ no $\% 20$ Brasil. pdf?fbclid=IwAR2RIDVCfpL25J86imLh2RBG5c5v4EHxbbvNlGON0WC3hJ_VUVGO5i5zGns

Cuervo, L., Welch, G., Maffioletti, L., \& Reategui, E. (2019). Musicalidade humana sob o prisma cognitivo-evolucionista: do Homo sapiens ao Homo digitalis. Revista OPUS, 23(2), 216-242. https:// doi.org/10.20504/opus2017b2310

Cuervo, L., \& Santiago, P. (2020). Percepções do impacto da pandemia no meio acadêmico da música. Revista Música da USP, 20(2), 357-378. https://doi.org/10.11606/rm.v20i2.180068

Freire, P. (1967). Educação como Prática da Liberdade. Paz e Terra.

Freire, P. (1970). Pedagogia do oprimido (17 a ed.). Paz e Terra.

Freire, P. (1981). Ação cultural para a liberdade (5ª ed.). Paz e Terra.

Freire, P. (1989). A importância do ato de ler: em três artigos que se completam. Cortez.

Freire, P. (1993). Pedagogía de la esperanza: un encuentro con pedagogía del oprimido. Siglo XXI.

Freire, P. (1996). Pedagogia da Autonomia: saberes necessários à prática educativa. Paz e Terra.

Gadotti, M. (2005). A questão da educação formal/não-formal [Palestra]. Seminário Direito à educação: solução para todos os problemas ou problema sem solução? Institut International Des Droits De L’enfant, Suíça.

Gainza, V. (1988). Estudos de Psicopedagogia Musical. Summus.

Green, L. (2008). Music, informal learning and the school: a new classroom pedagogy. Ashgate.

Levitin, D. (2016). The World in Six Songs: How the Musical Brain Created Human Nature. Penguin Books.

Oroza, E. (2012). Desobediencia tecnológica: de la revolución al revolico. http://www.ernestooroza.com/ desobediencia-tecnologica-de-la-revolucion-al-revolico

Paiva, V. (2016). Paulo Freire é terceiro teórico mais citado em trabalhos acadêmicos no mundo. https:// www.hypeness.com.br/2016/06/paulo-freire-e-terceiro-teorico-mais-citado-em-trabalhosacademicos-no-mundo/

Penna, M. (1995). Ensino de música: para além das fronteiras do conservatório. Em Y. Peregrino (Coord.), Da camiseta ao museu: o ensino das artes na democratização da cultura (pp. 129-140). Editora Universitária da UFPB.

Rodrigues, A., \& Cuervo, L. (2021). Desafios da docência no ensino remoto emergencial de música: reflexões e práticas na cultura digital. In: CONGRESO INTERNACIONAL EN MODALIDAD 
VIRTUAL PEDAGOGÍA, Ministerio de educación republica de Cuba, Havana, Cuba. https:// trabajos.pedagogiacuba.com/trabajos/49Desafios\%20da\%20Doc\%C3\%AAncia\%20no\%20 Ensino\%20Remoto\%20Emergencial\%20de\%20M\%C3\%BAsica.pdf

Schmidt, P. (2005). Music education as transformative practice: Creating new frameworks for learning music through a Freirian perspective. Visions of Research in Music Education, 6, 1-16.

Slamkowski, T. (2015). Freirean Pedagogy in Music Education [Tese de Mestrado, University of New Mexico]. UNM's Digital Repository. https:/digitalrepository.unm.edu/cgi/viewcontent. cgi? article $=1040 \&$ context $=$ mus_etds

Talbot, B., \& Williams, H. (2019). Critically Assessing Forms of Resistance in Music Education. Em D. Elliott, M. Silverman, \& G. McPherson (Eds.), The Oxford Handbook of Philosophical and Qualitative Assessment in Music Education (pp. 83-100). Oxford University Press. https://doi.org/10.1093/ oxfordhb/9780190265182.013.17 